\title{
Intraoperative TEE for the management of pul- monary tumour embolism during chondroblastic osteosarcoma resection
}

\author{
[L'ETO peropératoire comme mesure diagnostique d'une embolie tumorale pul- \\ monaire pendant la résection d'un ostéosarcome chondroblastique]
}

Lee Newkirk MD, ${ }^{*}$ Youri Vater MD, ${ }^{*}$ Donald Oxorn MD.CM FrCPC FACC, ${ }^{*}$ Michael Mulligan MD,$\dagger$ Ernest Conrad MD‡

\begin{abstract}
Purpose: Chondroblastic osteosarcoma requiring surgical intervention is associated with a high risk of pulmonary tumour embolism. Rapid intraoperative diagnosis with transesophageal echocardiography (TEE) allowed changing the management plan and treatment of a life-threatening pathology.
\end{abstract}

Clinical features: A 32-yr-old female with right pelvic chondrosarcoma presented for right hemipelvectomy. Two hours into the operation during ligation of the iliac blood vessels the patient's hemodynamic condition deteriorated and was followed by cardiac arrest. TEE was performed immediately and revealed massive tumour embolism in the right and left pulmonary arteries. Large tumour emboli were removed from the right and left pulmonary arteries after median sternotomy under cardiopulmonary bypass and moderate hypothermia. The hemipelvectomy was completed on the next day after fluid and inotropic agent resuscitation. An inferior vena cava filter was placed below the renal veins. The patient was discharged from hospital ten days after the surgery.

Conclusion: This case report illustrates the important role TEE can play in the early diagnosis and subsequent surgical treatment of noncardiac emergencies. Intraoperative TEE can have a significant impact on the decision making process in life threatening emergencies.

Objectif : La résection d'un ostéosarcome chondroblastique est une intervention associée à un haut risque d'embolie tumorale pulmonaire. Un diagnostic peropératoire rapide à l'aide de l'échocardiographie transœsophagienne (ETO) permet de modifier la conduite à tenir et le traitement de cette grave pathologie.

Éléments cliniques : Une femme de 32 ans atteinte d'un chondrosarcome pelvien droit s'est présentée pour une hémipelvectomie droite. Deux heures après le début de l'opération, pendant la ligature des vaisseaux iliaques, on a assisté à la détérioration de l'état hémodynamique, puis à un arrêt cardiaque. Une ETO, immédiatement réalisée, a révélé une embolie tumorale massive dans les artères pulmonaires droite et gauche. L'important embole tumoral a été retiré après une sternotomie réalisée sous circulation extracorporelle et hypothermie modérée. L'hémipelvectomie a été complétée le jour suivant, après traitement par correction volumétrique et médicaments inotropes. Un filtre-parapluie a été placé dans la veine cave inférieure en amont des veines rénales. La patiente a quitté l'hôpital dix jours après l'opération.

Conclusion : L'ETO peut jouer un rôle important dans le diagnostic précoce et le traitement chirurgical ultérieur d'urgences non cardiaques. L'ETO peropératoire peut influencer grandement les décisions à prendre quand la vie du patient est en danger.

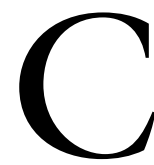

HONDROBLASTIC osteosarcoma requiring surgical intervention is associated with a high risk of pulmonary tumour embolism. ${ }^{1}$ Extensive thrombus formation in chondrosarcomas has been described in the femoral vein extending into the inferior vena cava, right atrium and left pulmonary artery (PA). ${ }^{1-3}$ Intravascular growth of tumour thrombi within the pulmonary trunk and its branches has been reported as well. ${ }^{1}$ In the majority of reported cases, the initial clinical signs of pulmonary tumour embolism were subacute and the final diagnosis was first established postmortem. However, intraoperative pulmonary tumour embolism can also have an acute onset with

From the Departments of Anesthesiology, ${ }^{*}$ Surgery, $†$ and Orthopedic Surgery, $\ddagger$ University of Washington Medical Center, Seattle, Washington, USA.

Address correspondence to: Dr. Youri Vater, Department of Anesthesiology, University Washington School of Medicine, POB 356540 ,

1959 Pacific Street, Seattle, WA 98195 USA. Phone: 206-598-4260; Fax 206-598-4544; E-mail: yvater@u.washington.edu

Accepted for publication April 1, 2003.

Revision accepted July 15, 2003. 
severe hemodynamic instability. We report the case of an acute intraoperative pulmonary tumour embolism during resection of a chondrosarcoma. Maintaining a high index of suspicion and the utilization of transesophageal echocardiography (TEE) allowed the immediate recognition and treatment of the underlying cause of hemodynamic instability.

\section{Case report}

A 32-yr-old female with osteoblastic chondrosarcoma of the right obturator ring presented for right hemipelvectomy. The patient first sought medical attention for symptoms of low back and right hip pain, which proved resistant to treatment with physical therapy and non-steroidal anti-inflammatory medication. A magnetic resonance imaging was obtained and revealed an $8 \times 8 \times 7 \mathrm{~cm}$ mass involving the right obturator ring and compressing the right femoral vessels. Biopsy was consistent with the diagnosis of high grade osteoblastic chondrosarcoma. Around the time of diagnosis, the patient began to experience intermittent shortness of breath, chest pain, and hemoptysis. Lower extremity venous duplex ultrasound scanning revealed a deep venous thrombosis (DVT) in the right external iliac vein. High resolution contrast tomography (CT) angiogram of the chest demonstrated multiple segmental pulmonary emboli. Anticoagulation with warfarin sodium tablets (coumadin) was instituted, and the international normalized ratio maintained at 2 . Prior to scheduling the surgical resection, adjuvant chemotherapy with doxorubicin and cisplatin was administered; however this failed to mitigate the rapid growth of the tumour. Anticoagulation was changed to low molecular weight heparin. A CT scan at this time was interpreted as showing small areas of pulmonary infarction as opposed to metastases.

Oriented and sedated with a short acting benzodiazepine, midazolam $2 \mathrm{mg} i v$, the patient was taken to the operating room with stable vital signs. Following the placement of an arterial line and two large bore iv lines, anesthesia was induced with etomidate and fentanyl, and vecuronium for muscle relaxation. The trachea was intubated and the lungs were ventilated mechanically.

Surgical dissection was carried down to the retroperitoneum and the brim of the right pelvis. The tumour was found to extend cranially to the external iliac vessels close to the bifurcation of the aorta, caudally to the obdurate foramen involving the sciatic nerve and displacing the bladder to the left, and posterior around the rectum.

Two hours into the operation and during the ligation of the iliac blood vessels the patient's hemody-

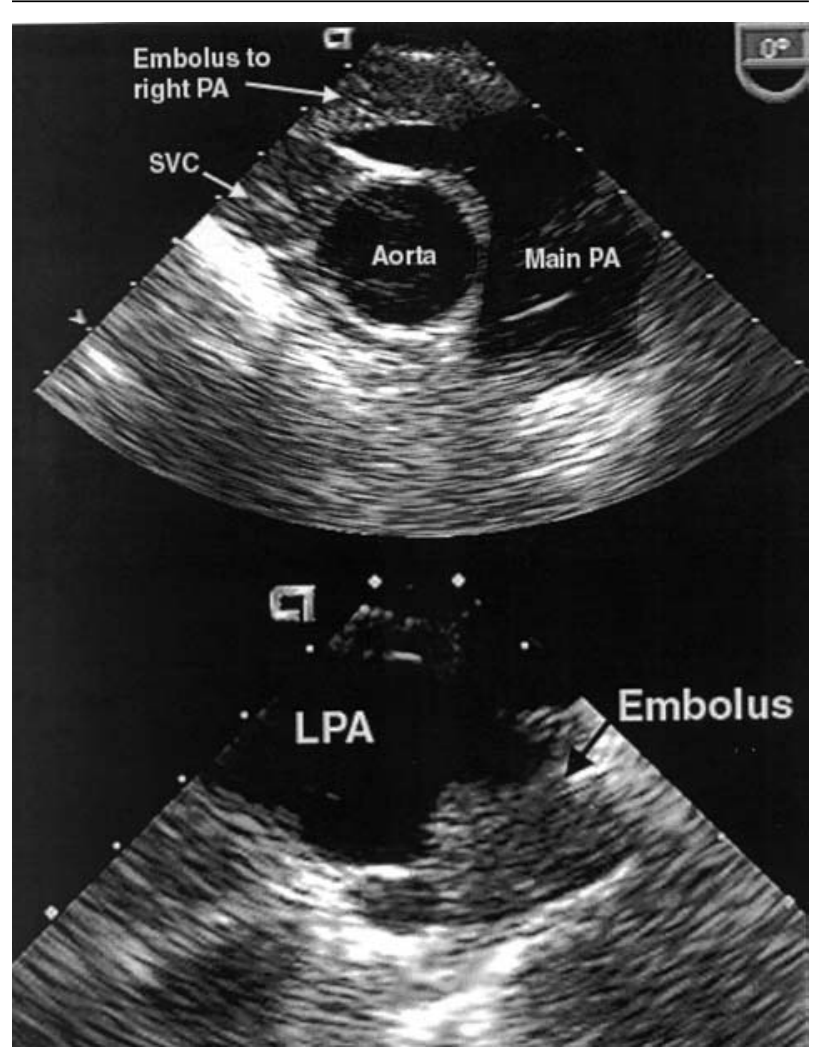

FIGURE 1 High esophageal transesophageal echocardiography images of the right (RPA) and left (LPA) pulmonary arteries.

Large embolic masses are seen. SVC $=$ superior vena cava.

namic condition suddenly deteriorated. Systolic blood pressure dropped from 120 to $85 \mathrm{mmHg}$, heart rate increased from 65 to 125 beats. $\mathrm{min}^{-1}, \mathrm{ETCO}_{2}$ decreased from $37 \mathrm{mmHg}$ to $12 \mathrm{mmHg}$ and $\mathrm{SpO}_{2}$ decreased from 98 to 78 . Pulseless electrical activity followed shortly thereafter despite large doses of epinephrine and vasopressin. Cardiopulmonary resuscitation was initiated while the groin incisions were being closed. A TEE probe was inserted and revealed a dilated and hypokinetic right ventricle and a hyperdynamic yet severely underfilled left ventricle. A large mass was seen in both the right and left PAs. (Figure 1). Severe tricuspid regurgitation and a right ventricular systolic pressure of $81 \mathrm{mmHg}$ were diagnosed by Doppler echocardiography, suggesting that there had been prior pulmonary hypertension.

A median sternotomy was performed and open cardiac massage was continued during cannulation of the right atrium and aorta. After initiation of emergency cardiopulmonary bypass (CPB) and cooling to $28^{\circ} \mathrm{C}$, 


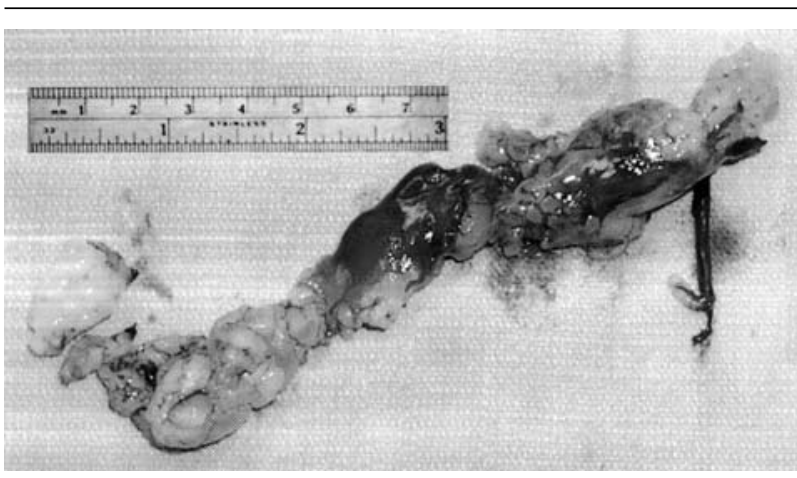

FIGURE 2 The mass removed from the right pulmonary artery.

the PAs were incised. A $1 \times 4.5 \mathrm{~cm}$ mass was removed from the left PA, and a $2 \times 5.2 \mathrm{~cm}$ mass from the right PA. On the right, it was noted that the tumour had become adherent to the vascular wall of the right upper lobar artery and the distal portion of the right lower lobar artery. (Figure 2).

The patient was weaned from $\mathrm{CPB}$ with infusions of vasopressin $6 \mathrm{U} \cdot \mathrm{hr}^{-1}$, milrinone $0.5 \mu \mathrm{g} \cdot \mathrm{kg}^{-1} \cdot \mathrm{min}^{-1}$ and epinephrine $0.02 \mu \mathrm{g} \cdot \mathrm{kg}^{-1} \cdot \mathrm{min}^{-1}$. Nitric oxide 40 ppm was added to the inhaled gases. The hemipelvectomy was postponed and the patient was transferred to the intensive care unit (ICU) intubated and ventilated mechanically.

Twelve hours after arrival in the ICU the patient's cardiovascular condition was reevaluated by TEE. Right ventricular function had improved significantly and Doppler derived right ventricular systolic pressure had decreased to $42 \mathrm{mmHg}$. The calculated ejection fraction using the apical biplane method was $59.7 \%$.

The patient was sedated and no neurological damage was apparent. Milrinone $0.375 \mu \mathrm{g} \cdot \mathrm{kg}^{-1} \cdot \mathrm{min}^{-1}$ and vasopressin $2 \mathrm{U} \cdot \mathrm{hr}^{-1}$ were used in the ICU during the first $24 \mathrm{hr}$ to support the cardiovascular system.

Twenty-four hours after the pulmonary embolic event and cardiopulmonary resuscitation, a vena caval filter was placed and the right hemipelvectomy completed uneventfully. On follow-up after surgery, the tumour had recurred and was deemed inoperable. The patient was discharged home and died two months after the operation.

\section{Discussion}

Osteosarcoma tumour embolisms in the PA tree causing acute cardiovascular instability, cardiac arrest and death are rare clinical events. ${ }^{1}$ Only a few cases of osteosarcoma pulmonary tumour embolism have been reported. ${ }^{2,4-8}$ In patients with chondrosarcoma presenting symptoms such as shortness of breath, primary pulmonary tumour embolism has often been detected first on postmortem examination. ${ }^{4,9,10}$ A series of autopsies discovered pulmonary tumour emboli in $8.3 \%$ of cases and considered they had contributed to the death of the patient. ${ }^{1}$ Autopsies revealed occlusions of the main pulmonary arterial trunk by embolism with extension into the right and left PAs and their branches. ${ }^{1}$ A case of complete obliteration of the large and small PAs by tumour in a patient with osteoblastic sarcoma extending from the sacrum to the PAs has been reported. ${ }^{3}$ Most patients with osteosarcoma tumour embolism have a subacute presentation of pulmonary embolism. ${ }^{11-14} \mathrm{~A}$ confounding factor in the management of these events is that DVT and pulmonary embolism occur frequently in osteosarcomas due to the tendency of the tumour to result in hypercoagulability and thrombus formation, ${ }^{15-17}$ and subsequent pulmonary embolization of clot. ${ }^{18,19}$ Hypercoagulability is, in fact, the main cause of morbidity and mortality in patients with osteosarcoma. ${ }^{20}$ There is currently no agreement on the optimal anti-thrombotic prophylaxis regimen. ${ }^{21-24}$ In this case, the patient suffered a massive intraoperative pulmonary tumour embolism despite anti-coagulation. The pathologist's report following the event confirmed the presence of a metastatic high grade osteosarcoma, of the chondroblastic subtype.

TEE is an invaluable adjunct in the diagnostic approach to the patient with unexplained, intraoperative hemodynamic instability, as it can rapidly yield information on right and left ventricular systolic function, intravascular volume status, and the presence of obstructing lesions such as pericardial tamponade and intracardiac masses. ${ }^{25-28}$ The hemodynamic variables and end-tidal carbon dioxide measurements in this patient suggested an embolic event, but TEE demonstrated that the embolic material was solid and pinpointed the anatomic location, thus facilitating surgery and documenting postoperative resolution. ${ }^{29}$ The hemodynamic alterations observed were also compatible with air embolism. The appearance of air in the right heart chambers would have altered the therapeutic approach.

When examining a patient with suspected pulmonary embolism, extra attention should be paid to right heart function, the degree of left ventricular filling, interventricular septal motion, tricuspid and pulmonic valve integrity, the interatrial septum (where a patent foramen ovale may be detected), and the size and patency of the main PAs. ${ }^{30,31}$ Rapid TEE diagno- 
sis can lead to prompt surgical embolectomy and may provide high survival rates during life threatening PA embolism. ${ }^{32}$ The right ventricular outflow tract, pulmonic valve, and right main PA are easily imaged at the high esophageal level; the left PA is more difficult to visualize due to interposition of the left main bronchus. The impact of TEE in the noncardiac setting sometimes is even more important than in cardiac surgery suite..$^{33,34}$

In summary, this case reports the important role TEE can play in the early diagnosis and subsequent successful surgical treatment of noncardiac intraoperative emergencies. ${ }^{33-35}$ TEE was a major contributor to the successful management of a patient with intraoperative osteoblastic chondrosarcoma tumour embolism.

\section{References}

1 Abmed AA, Heller DS. Fatal pulmonary tumor embolism caused by chondroblastic osteosarcoma. Arch Pathol Lab Med 1999; 123: 437-440.

2 Booth AJ, Tweed CS. Case report: fatal pulmonary embolism due to osteogenic sarcoma in a child. Clin Radiol 1989; 40: 533-5.

3 Hanh W, Oltmanns G, von Paris V, Batz C, Basche S, Nagel F. Acute cor pulmonale as a sequela of tumor embolism (German) Z Gesamte Inn Med 1991; 46: 134-6.

4 Wakasa K, Sakurai M, Uchida A, Yoshikawa H, Maeda $A$. Massive pulmonary tumor emboli in osteosarcoma. Occult and fatal complication. Cancer 1990; 66: 583-6.

5 Leung DY, Seah PW, Lee LC, Cranney GB, Walch WF. Embolic chondrosarcoma: an unusual cause of pulmonary embolism. Am Heart J 1993; 126: 732-4.

6 Yutani C, Imakita M, Ishibashi-Ueda H, Katsuragi M, Yoshioka T, Kunieda T. Pulmonary hypertension due to tumor emboli: a report of three autopsy cases with morphological correlations to radiological findings. Acta Pathol Jpn 1993; 43: 135-41.

7 Shepard JA, Moore EH, Templeton PA, McLoud TC. Pulmonary intravascular tumor emboli: dilated and beaded peripheral pulmonary arteries at CT. Radiology 1993; 187: 797-801.

8 Schwarz MI, Goldman AL, Roycroft DW, Hunt KK. Vascular invasion by chondrosarcoma simulating pulmonary emboli. Am Rev Respir Dis 1972; 106: 109-13.

9 Tosbida K, Miyashita N, Nakajima M, Niki , Matsushima T. A case of sternal chondrosarcoma with multiple pulmonary embolisms (Japanese). Nihon Kokyuki Gakkai Zasshi 2002; 40: 166-70.

10 Mangiapan G, Parrot A, Antoine M, Mayaud C. Pulmonary artery hypertension due to tumor microem- bolism (French). Rev Mal Respir 1995; 12: 62-5.

11 Lee FY, Mankin HJ, Fondren G, Gebhardt MC, Springfeld DS. Chondrosarcoma of bone: an assessment of outcome. J Bone Joint Surg Am 1999; 81-A: 326-38.

12 Mullins FX, Minton JP. Surgical management of recurrent pulmonary emboli preceding hemipelvectomy for chondrosarcoma. Am J Surg 1965; 110: 951-5.

13 Langlais F, Lambotte JC, Thomazean H. Long-term results of hemipelvis reconstruction with allografts. Clin Orthop 2001; 388: 178-86.

14 Soares FA. Fatal pulmonary tumor embolism caused by chondroblastic osteosarcoma (Letter). Arch Pathol Lab Med 2000; 124: 661.

15 Joung S, Robinson B. Venous thromboembolism in cancer patients in Christchurch, 1995-1999. N Z Med J 2002; 115: 257-60.

16 Fichaux $O$, de Muret A, Dessene X, et al. Cardiac metastasis of chondrosarcoma: a case report (French). Ann Cardiol Angeiol (Paris) 1998; 47: 165-8.

17 Pring ME, Weber KL, Unni KK, Sim FH. Chondrosarcoma of the pelvis: a review of sixty- four cases. J Bone Joint Surg Am 2001; 83-A: 1630-42.

18 Woodring JH, Bognar B, van Wyk CS. Metastatic chondrosarcoma to the lung with extension into the left atrium via invasion of the pulmonary veins. Presentation as embolic cerebral infarction. Clin Imaging 2002; 26: 338-41.

19 Hoekstra HJ, Pras B, Mooyaart EL, van Ginkel R, Molenaar WM. Pelvic girdle chondrosarcoma and inferior vena cava thrombosis. Eur J Surg Oncol 1997; 23: 577-9.

20 Agorogiannis EI, Agorogiannis GI. Coagulation, angiogenesis, and venous thromboembolism in cancer (Letter). Lancet 2002; 359: 1440.

21 Gately S, Twardowski P, Stack MS, et al. The mechanism of cancer-mediated conversion of plasminogen to the angiogenesis inhibitor angiostatin. Proc Natl Acad Sci 1997; 94: 10868-72.

22 Lip GY, Chin BS, Blann AD. Cancer and the prothrombotic state. Lancet Oncol 2002; 3: 27-34.

23 Sutherland DE, Weitz IC, Liebman HA.

Thromboembolic complications of cancer: epidemiology, pathogenesis, diagnosis, and treatment. Am J Hematol 2003; 72: 43-52.

24 Bergqvist D, Agnelli G, Cohen AT, et al. Duration of prophylaxis against venous thromboembolism with enoxaparin after surgery for cancer. N Engl J Med 2002; 346: 975-80.

25 Gandhi AK, Pearson AC, Orsinelli DA. Tumor invasion of the pulmonary veins: a unique source of systemic embolism detected by transesophageal echocardiography. J Am Soc Echocardiogr 1995; 8: 97-9. 
26 Quattara A, Boccara G, Chiche L, Coriat P. Intraoperative diagnosis of an unsuspected left atrial myxoma by transesophageal echocardiography. Anesth Analg 2002; 94: 1458-9.

27 Huttemann E, Schelenz C, Franke U, Schlichter A, Reinhart $K$. Transesophagal echocardiography and intraoperative management of patients with renal cell carcinoma and rena cava extension (German). Anaesthetist 2002; 51: 116-9.

28 Hong CL, Ho AC, Liu HP, et al. Diagnosis of progressive compression of the aortic true lumen with intraoperative transesophageal echocardiography during repair of dissection of thoracic aorta-a case report. Acta Anaesthesiol Sin 2001; 39: 183-7.

29 Roewer N, Beck H, Kochs E, et al. Detection of venous embolism during intraoperative monitoring by twodimentional transesophageal echocardiography (German). Anasth Intensivther Notfallmed 1985; 20: 200-5.

30 Koessler MJ, Fabiani R, Hamer H, Pitto RP. The clinical relevance of embolic events detected by transesophageal echocardiography during cemented total hip arthroplasty: a randomized clinical trial. Anesth Analg 2001; 92: 49-55.

31 Sivaram CA, Craven P, Chandrasekaran K. Transesophageal echocardiography during removal of central venous catheter associated with thrombus in superior vena cava. Am J Card Imaging 1996; 10: 266-9.

32 Pargger H, Stulz P, Friedli D, Gachter A, Gradel E, Skarvan $K$. Massive intraoperative pulmonary embolism. Diagnosis and control following embolectomy with transesophageal echocardiography (German). Anaesthesist 1994, 43: 398-402.

33 Denault AY, Couture P, McKenty S, et al. Perioperative use of transesophageal echocardiography by anesthesiologists: impact in noncardiac surgery and in the intensive care unit. Can J Anesth 2002; 49: 287-93.

34 Couture P, Denault AY, McKenty S, et al. Impact of routine use of intraoperative transesophageal echocardiography during cardiac surgery. Can J Anesth 2000; 47: 20-6.

35 Suriani RJ, Neustein S, Shore-Lesserson L, Konstadt S. Intraoperative transesophageal echocardiography during noncardiac surgery. J Cardiothorac Vasc Anesth 1998; 12: 274-80. 